\title{
Aspects of body balance characteristics of novice fencers
}

Liliana Elisabeta Radu ${ }^{a^{*}}$

Paula Drosescu ${ }^{b}$

Cristian Mihail Rus ${ }^{\mathrm{c}}$

Gynetta Vanvu ${ }^{\text {d }}$

Suggested Citation:

Abstract 
1. Introduction

2. Material and Method

2.1. Subjects 
2.2. Procedures

2.2.1. Balance Tests

2.2.2. Physical fitness test

\subsection{Analysis}

3. Results 
Table 1. Variables of balance in standing position

Table 2. Variables of balance in fencing position

Table 3. Standing position with eyes open - correlation 
Table 5. Fencing position with eyes open - correlation

4. Discussion 


\section{References}



- 